\section{Christian Bonnerot Claire Hivroz}

\title{
Signalisation et transport intracellulaire des immunorécepteurs
}

Des récepteurs spécifiques exprimés par les cellules immunocompétentes reconnaissent les antigènes : l'immunoglobuline membranaire exprimée par les lymphocytes B (BcR) les reconnaît sous forme soluble ; le récepteur de l'antigène des lymphocytes $T$ (TcR) reconnaît le complexe peptide antigénique-CMH exprimé à la surface des cellules présentatrices. D'autres récepteurs exprimés à la surface des macrophages ou des cellules dendritiques reconnaissent la partie constante des anticorps complexés à un antigène (FCR). La liaison de ces récepteurs à leurs ligands induit une cascade d'événements aboutissant à l'activation des cellules et à l'internalisation des complexes formés dans des vésicules, qui sont ensuite transportés dans des endosomes et des lysosomes. Dans les cas du BcR et du FcR, il existe ainsi un ciblage des antigènes dans des compartiments spécialisés où ils sont apprêtés et associés à des molécules du CMH de classe II puis présentés à la surface des cellules. Un couplage des phénomènes de signalisation et d'internalisation vient d'être démontré au sein d'une même unité moléculaire et fonctionnelle.

'acquisition d'une immunité nécessite le développement d'une coopération entre les différentes cellules du système immunitaire. Un antigène doit être capté par les lymphocytes B, les macrophages ou les cellules dendritiques qui l'apprêtent en peptides d'une douzaine d'acides aminés s'associant, dans la voie endosomique, aux molécules de classe II du complexe majeur d'histocompati- bilité (CMH). Ce complexe CMH-IIpeptide est alors transporté à la surface des cellules présentatrices où il stimule des lymphocytes $T$ qui réagissent en sécrétant des lymphokines réglant les fonctions effectrices des cellules du système immunitaire (figure 1).

La coordination et la spécificité de la réponse immunitaire est assurée par une famille de récepteurs qui reconnaissent les antigènes dans différents 
états, les immunorécepteurs : le récepteur BcR qui reconnaît un antigène soluble à la surface des lymphocytes B par l'intermédiaire d'une immunoglobuline membranaire, les FcR qui permettent la liaison d'un antigène complexé à des anticorps à la surface des macrophages ou des cellules dendritiques. Les complexes CMH-peptides exprimés par les cellules présentatrices sont détectés spécifiquement par les récepteurs de l'antigène des lymphocytes $\mathrm{T}$ (TcR) [1]. Bien que les ligands de chacun de ces récepteurs soient fondamentalement différents, ils partagent une grande homologie structurale et fonctionnelle. BcR, FcR et TcR sont composés d'un module de une à deux chaînes capables de reconnaître leur ligand et d'un module [2, 3] de deux à six chaînes qui portent, dans leur région intracytoplasmique, un même motif peptidique constitué de deux résidus tyrosine distants de dix acides aminés, appelé ITAM (immunoreceptors tyrosine-based activating motif) (figure 2) [4, 5]. Ce motif peptidique permet de coupler ces récepteurs à différents effecteurs cytoplasmiques, qui mettent en route la transduction de signaux et l'internalisation du récepteur ou du complexe récepteur-ligand, événement fondamental dans la régulation de la réponse immune (figure 1).

\section{Signalisation et transport intracellulaire des immunorécepteurs}

L'analyse des voies de transduction utilisées par ces différents récepteurs a permis de proposer un schéma général des événements intracellulaires qui déclenchent l'activation des cellules du système immunitaire. En l'absence de ligands, les différentes sous-unités transductrices sont maintenues sous forme non phos-

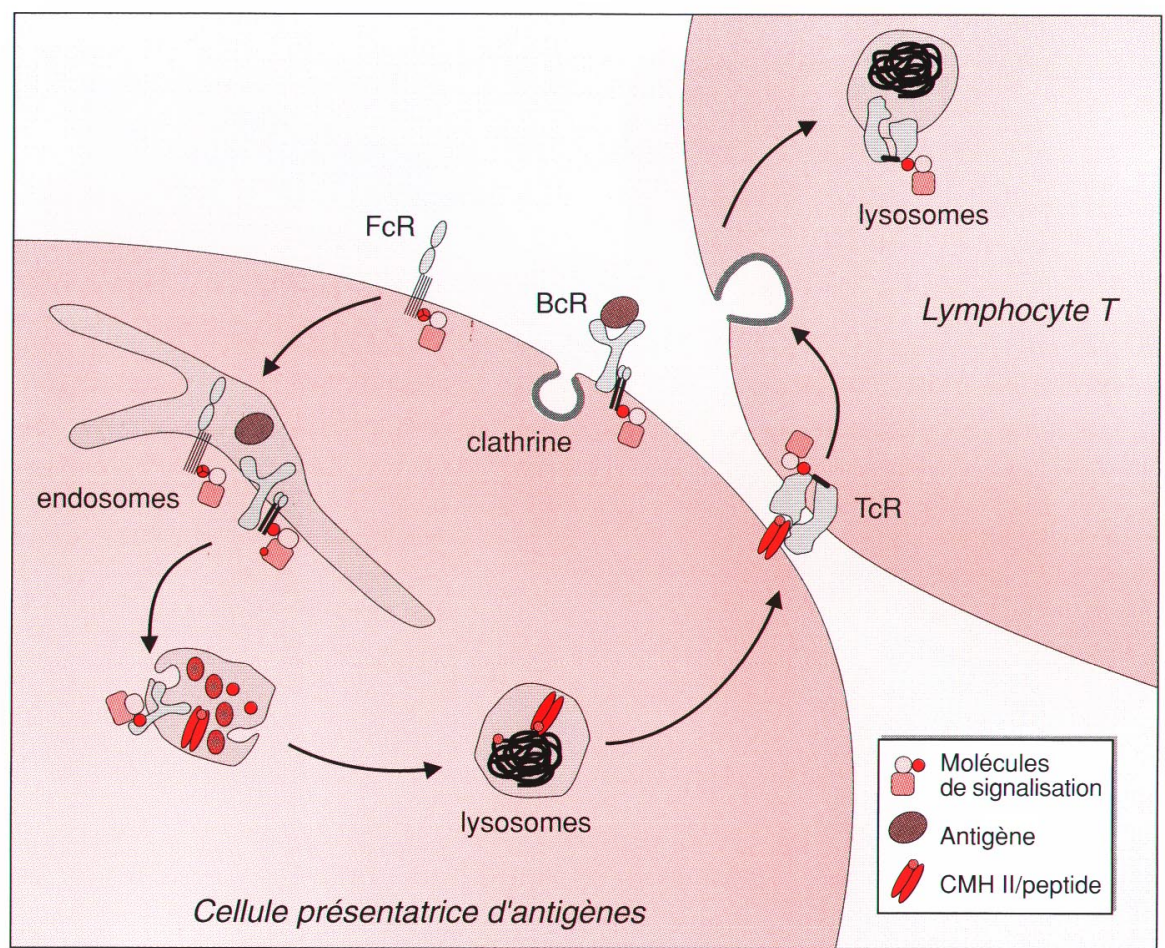

Figure 1. Diagramme schématique des événements de transport intracellulaire des BcR, FcR et TCR. La liaison des récepteurs à leurs ligands induit leur internalisation et leur transport dans la voie endosomale. Dans le cas du BcR et des $F c R$, ces événements permettent le transport de l'antigène dans des compartiments intracellulaires spécialisés dans lesquels les antigènes sont apprêtés et présentés par des molécules du CMH de classe II. Les complexes CMH-peptides ainsi réexprimés permettent l'activation de clones $T C D 4^{+}$spécifiques de ces complexes. phorylées. L'engagement des récepteurs rompt cet équilibre et induit la phosphorylation des résidus tyrosine des ITAM et le recrutement de différentes tyrosine-kinases de la famille Src. Les ITAM, phosphorylés sur les deux résidus tyrosine de certaines des sous-unités, sont alors reconnus par les deux domaines SH2 (src homology domain de type II) des tyrosinekinases Syk [6-8] ou ZAP70, en fonction des types cellulaires (figure 2). Le recrutement de Syk ou de ZAP70 est à l'origine de l'induction conjointe de différentes voies d'activation cellulaire. Tout d'abord l'activation de la phospholipase $\mathrm{C} \gamma$ qui hydrolyse les phospholipides membranaires en diacylglycérol (activateur de la protéine-kinase $\mathrm{C}$ ) et en inositol 1,4,5 phosphate (IP3) permettant l'élévation de la concentration calcique intracellulaire [9] et donc l'activation de protéines dépendantes du calcium. Parallèlement, les tyrosinekinases de la famille Syk activent la voie ras qui aboutit à l'activation des MAP kinases et à la translocation vers le noyau de protéines induisant la transcription de nombreux gènes. Enfin, les immunorécepteurs sont capables d'interagir et d'activer la phosphatidyl inositol 3 kinase (PI3K) [10] qui règle la voie d'activation dépendante de ras. Cette enzyme, initialement co-purifiée avec la p60 $0^{\text {src }}$ et le middle T antigen de SV40, a été également impliquée dans le contrôle d'événements de transports intragolgiens et endosomiques grâce à l'utilisation d'un inhibiteur spécifique, la wortmannine, et à l'identification d'un mutant de la levure [11, 12].

Bien que les mécanismes moléculaires de l'endocytose des différents immunorécepteurs n'aient pas été entièrement caractérisés, un schéma général peut néanmoins être proposé. Les sous-unités des immunorécepteurs interagissent, par leurs régions cytoplasmiques, avec les complexes adaptateurs AP2, permettant le recrutement des tri-squelettes de clathrine puis l'invagination de la membrane plasmique qui aboutit à la formation d'une vésicule recouverte de clathrine. Après dépolymérisation du réseau de clathrine, les vésicules portant les récepteurs fusionnent avec les endosomes où ils sont triés soit vers la surface cellulaire, où ils 


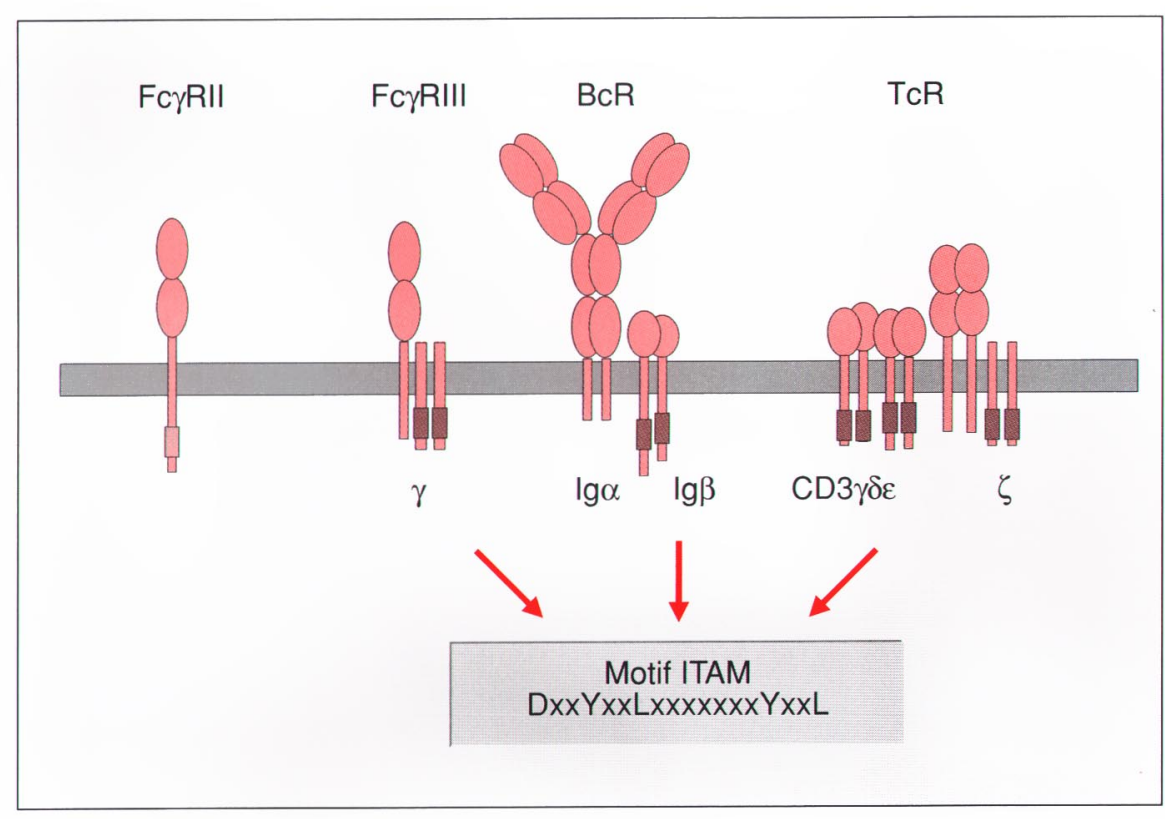

Figure 2. Homologies structurales et fonctionnelles des immunorécepteurs. Les immunorécepteurs sont composés d'un module de reconnaissance de l'antigène qui porte la spécificité de cette reconnaissance et d'un module de signalisation. La reconnaissance de l'antigène, sous forme soluble pour le $B c R$, sous forme complexé à des immunoglobulines pour les FcR, ou sous forme de complexe CMH-peptide pour le TcR, induit la phosphorylation des ITAM présents sur les chaînes qui composent les modules de signalisation.

pourront subir un nouveau cycle d'internalisation, soit vers les lysosomes où ils pourront être dégradés ainsi que leurs ligands respectifs. L'internalisation des immunorécepteurs intervient dans deux situations qu'il est nécessaire de bien différencier: d'une part, l'internalisation constitutive des récepteurs, c'est-àdire en l'absence de liaison du ligand, et, d'autre part, l'internalisation des récepteurs agrégés par l'interaction avec leurs ligands spécifiques.

Il apparaît donc que le même stimulus, c'est-à-dire la reconnaissance d'un antigène par un BcR, d'un complexe antigène-anticorps par un FcR ou d'un complexe CMH-peptide par un TcR, aboutit au démarrage d'une cascade d'événements intracellulaires qui déterminent conjointement l'activation des cellules et d'une boucle de rétrocontrôle passant par la dégradation du récepteur dans des compartiments lysosomiaux. Ce schéma général (figure 1) fait apparaître une grande communauté des endosomique $[3,15,16]$. La diversité moléculaire des FcR et des BcR suggère qu'ils interagissent avec des effecteurs cytoplasmiques différents qui pourraient intervenir sur leur transport dans la voie endosomique.

La diversité du BcR à la surface des lymphocytes B est liée, d'une part, à la spécificité de reconnaissance des régions variables des immunoglobulines et, d'autre part, à la classe des immunoglobulines membranaires ( $\operatorname{Ig} \mathrm{M}, \operatorname{IgD}, \operatorname{Ig} \mathrm{G}, \operatorname{Ig} \mathrm{A}$ et $\operatorname{IgE}$ ) qui s'associe ou non à un hétérodimère de deux sous-unités, Ig- $\alpha / \operatorname{Ig}-\beta$. Ces trois niveaux de diversité moléculaire du BcR semblent intervenir sur la capacité des BcR de moduler la présentation antigénique par les molécules de classe II du CMH. En effet, les régions variables déterminent l'affinité de l'immunoglobuline pour l'antigène, donc la stablité et le transport du complexe antigène-immunoglobuline dans la voie endosomique [17] tandis que l'isotype détermine la présence d'une région intracytoplasmique de la chaîne lourde qui permet l'internalisation d'un antigène par l'intermédiaire d'un motif du type YxxM présent dans les IgG, les IgA et les IgE [18]. Par ailleurs, les deux sous-unités de l'hétérodimère Ig- $\alpha / \operatorname{Ig}-\beta$ comportent chacune dans leur région intracytoplasmique un ITAM [4] - qui, bien que très homologue, ne transmet pas les mêmes signaux intracellulaires [1922] - et n'adressent pas l'antigène dans les mêmes compartiments intracellulaires [23]. Sur le plan fonctionnel, il a aussi été établi que les signaux de ciblage présents dans les régions intracytoplasmiques d'Ig- $\alpha$ et d'Ig- $\beta$ induisent la présentation de complexes CMH-peptides différents [24]. La variabilité de structure du $\mathrm{BcR}$ pourrait aussi être un paramètre important dans le contrôle de la réponse immunitaire.

Bien que la diversité des FcR soit moindre, un certain nombre d'analogies sont en fait apparentes. Tout d'abord, des récepteurs de forte affinité (Kd $10^{-7}$ à $10^{-9}$ ) (dits de type I) ou de faible affinité (Kd $10^{-5}$ à $10^{-6}$ ) (dits de type II ou III) pour la plupart des classes d'immunoglobulines [25] ont été mis en évidence. Par ailleurs, certains de ces récepteurs, comme le Fc $\gamma$ RIIB ou le Fc $\gamma$ RI, sont monocaténaires et comportent un 
signal d'internalisation dans leur région intracytoplasmique, alors que d'autres, multicaténaires, sont composés d'une chaîne impliquée dans la liaison de l'immunoglobuline ainsi que deux ou trois chaînes portant chacune un ITAM (figure 2). La comparaison des FcyRII et III a permis de mieux comprendre les mécanismes moléculaires de la présentation antigénique [16, 26]. Les deux sont, en effet, capables d'induire l'internalisation d'un complexe antigène-anti-

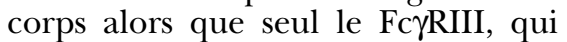
est composé d'un homodimère de chaîne $\gamma$, est capable de déclencher une cascade de transmission du signal intracellulaire à travers l'ITAM contenu dans la région intracellulaire de la chaîne $\gamma$ [3]. Ces deux récepteurs se différencient aussi par leur transport dans la voie endosomique [27] et, fonctionnellement, par leur capacité d'induire la présentation d'un spectre de complexes CMH-peptides différents [28].

Ces différences fonctionnelles et moléculaires observées entre les Fc $\gamma$ RII et III [27, 28], ou entre les sous-unités Ig- $\alpha$ et Ig- $\beta$ du BcR [19, 20,22-24] suggéraient que cette triple corrélation entre un tri sélectif dans la voie endosomique, la capacité d'enclencher une cascade de transmission du signal intracellulaire et la présentation d'un large spectre de complexes CMH-peptides, pourrait être déterminée par des effecteurs cytoplasmiques communs.

Pour aborder cette question, nous avons entrepris une mutagenèse extensive des régions intracytoplasmiques de la chaîne $\gamma$ (associée au Fc $\gamma$ RIII) et des molécules Ig- $\alpha$ et Ig- $\beta$ (associées au BcR) à la recherche de mutations qui affectent spécifiquement la capacité de ces récepteurs de transmettre un signal d'activation sans altérer l'endocytose relayée par ces mêmes récepteurs. Nous avons ainsi mis en évidence des mutations, dans les ITAM de la chaîne $\gamma$ et des molécules Ig- $\alpha$ et Ig- $\beta$, qui affectent leur capacité de transduction sans modifier leur taux d'internalisation $[24,27]$. Ces mêmes mutations abolissent le transport du récepteur vers des compartiments lysosomiaux et la présentation de différents peptides associés aux molécules de classe II du $\mathrm{CMH}$. En terme de transmission du chent la phosphorylation des résidus tyrosine des ITAM puis le recrutement et l'activation de la tyrosine kinase Syk [24, 27] suggérant un rôle de Syk dans le tri de ces immunorécepteurs vers des compartiments d'apprêtement de l'antigène.

La tyrosine-kinase Syk est une protéine de $70 \mathrm{kDa}$ constituée de deux domaines SH2 séparés par un domaine bcr et associé à un domaine kinase [29]. La fonction du domaine bcr est inconnue. Les deux domaines SH2 s'associent aux deux tyrosines phosphorylées des ITAM en activant le domaine kinase de Syk qui s'autophosphoryle et recrute différents effecteurs [6, 8] (figure 3). En surexprimant, dans des cellules présentatrices, un mutant dominant négatif de la protéine Syk, correspondant aux deux domaines $\mathrm{SH} 2$, nous avons montré que l'inhibition du recrutrement de Syk affecte le transport de certains immunorécepteurs vers des compartiments lysosomiaux et la présentation de nombreux épitopes $\mathrm{T}$. Ces résulats ont ainsi établi le rôle de
Syk dans le transport intracellulaire des antigènes et la présentation antigénique relayée par les $\mathrm{FcR}$ et les BcR.

Puisque Syk est capable d'interagir ou d'activer d'autres protéines cytoplasmiques, celles-ci pourraient représenter les véritables effecteurs du transport intracellulaire des immunorécepteurs vers des compartiments de dégradation.

\section{TcR}

L'activation des lymphocytes T nécessite la reconnaissance par le récepteur T (TcR) du complexe CMH-peptide présent sur la cellule présentatrice de l'antigène (CPA). Le récepteur $T$ de l'antigène est un complexe multiprotéique composé d'un hétérodimère $\alpha \beta$ clonotypique ainsi que des hétérodimères CD3- $\gamma \delta$, CD3- $\delta \varepsilon$ et d'un homodimère $\zeta \zeta$. Alors que l'hétérodimère $\alpha \beta$ est responsable de la spécificité de reconnaissance de l'antigène, les chaînes du CD3 et l'homodimère $\zeta$ sont nécessaires à la transduction des

Reconnaissance de l'antigène agrégation des récepteurs

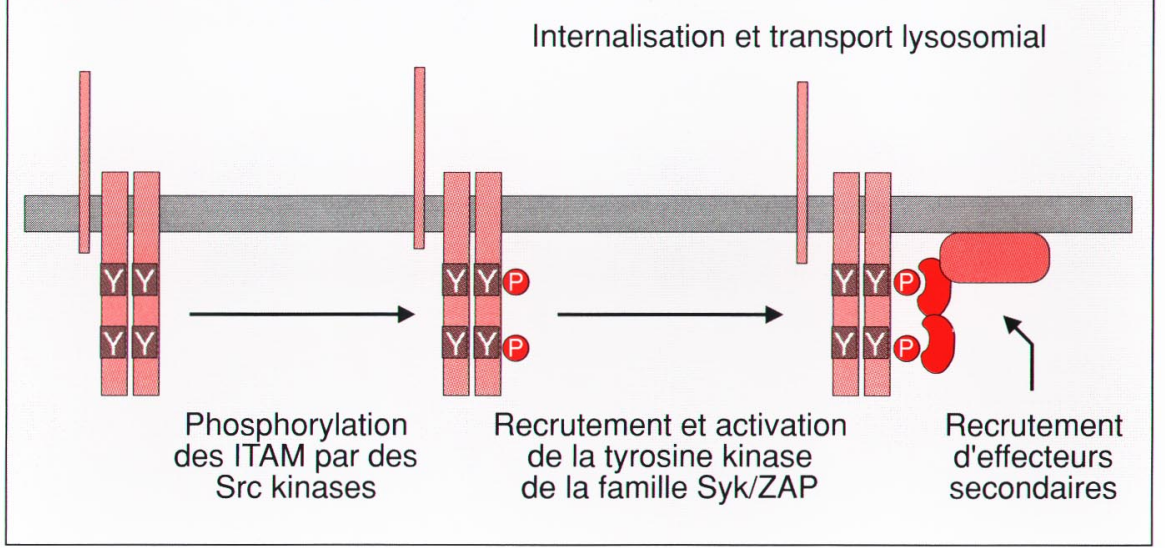

Figure 3. Événements précoces induits par l'activation du BcR, du FcR ou du TcR. La liaison du BcR, du FcyRlll ou du TcR à leurs ligands respectifs induit une agrégation de ces récepteurs suivie de leur internalisation. Parallèlement, les chaînes Ig $\alpha$ et $\lg \beta$, associées au BcR, ou la chaîne $\gamma$, associée au FcR $\gamma$ III, ou les chaînes $\gamma, \delta \varepsilon$ du CD3 et l'homodimère $\zeta-\zeta$ associés au TcR sont phosphorylés sur les ITAM par des tyrosine-kinases de la famille Src. Ces phosphorylations permettent l'association des tyrosine-kinases Syk/ZAP et le recrutement d'effecteurs secondaires. Parallèlement, les immunorécepteurs qui ont été stimulés sont internalisés et transportés vers les lysosomes où ils sont dégradés. La phosphorylation des ITAM et le recrutement de Syk contrôlent les événements de transport du BcR et du FcR dans la voie endosomique ainsi que leur capacité de présenter des antigènes. 
signaux qui conduiront à l'activation des lymphocytes $\mathrm{T}$ (figure 2).

La reconnaissance par le lymphocyte $\mathrm{T}$ de l'antigène présent à la surface de la cellule présentatrice de l'antigène (figure 1) induit une cascade d'événements biochimiques et en particulier une augmentation de la concentration en $\mathrm{Ca}^{2+}$ intracytoplasmique $\left(\left[\mathrm{Ca}^{2+}\right] \mathrm{i}\right)[30,31]$. La fréquence, la durée et l'intensité de cette augmentation de $\left[\mathrm{Ca}^{2+}\right] \mathrm{i}$ sont finement réglées et contrôleront à leur tour la transcription de gènes [32, 33]. Ces différents paramètres sont eux-mêmes réglés par l'engagement et la stimulation sériés de nombreux TcR par un petit nombre de complexes CMH-peptide [34]. La régulation de l'expression de surface du complexe CD3/TcR joue donc un rôle important dans l'activation des lymphocytes $\mathrm{T}[34,35]$. Il existe deux niveaux de régulation de cette expression. Le premier niveau consiste dans le contrôle de l'assemblage et du transport intracellulaire des différents composants du complexe [36]. Le second niveau a lieu directement à la surface, ainsi les complexes CD3/TcR sont constitutivement internalisés et recyclés [37]. De plus, l'une des caractéristiques de la reconnaissance de l'antigène par le lymphocyte $\mathrm{T}$ est qu'elle s'autocontrôle: l'interaction TcR/CMHpeptide induit en effet une diminution de l'expression des complexes TcR qui ont été stimulés [34, 35].

Ainsi, la diminution d'expression du TcR conduit à l'extinction du signal donné par la formation des conjugués T-CPA. De plus, le fait qu'un complexe CD3/TcR ne puisse être stimulé qu'une fois, puisqu'il est ensuite internalisé, assure un contrôle strict de la durée et de l'intensité de l'activation des lymphocytes $\mathrm{T}$ par le nombre de déterminants antigéniques disponibles. Plusieurs observations ont mis en évidence l'importance d'une régulation de l'expression du complexe CD3/TcR comme moyen de contrôler la signalisation par le TcR et la stimulation antigénique. Une régulation négative de l'expression du CD3/TcR, et en particulier de la chaîne $\zeta$, a été démontrée dans un certain nombre de cas et semble être à l'origine de la suppression d'une réponse $\mathrm{T}$ spécifique de l'antigène.
La modulation a également été proposée comme mécanisme de l'anergie.

Dans plusieurs situations pathologiques, il a été démontré que l'expression du CD3/TcR pouvait être diminuée. Plusieurs travaux ont montré que la chaîne $\zeta$ n'est pas présente dans les complexes CD3/TcR de lymphocytes $\mathrm{T}$ purifiés à partir de patients atteints de tumeurs [38]. Cette même observation a été faite dans les lymphocytes $\mathrm{T}$ de souris porteuses de tumeurs [39]. La compréhension des mécanismes à l'origine de la modulation d'expression du CD3/TcR pourrait permettre de comprendre l'absence de réponse $\mathrm{T}$ spécifique de l'antigène dans un certain nombre de situations pathologiques et peut-être d'y remédier.

Les mécanismes de modulation de l'expression du CD3/TcR ne sont pas entièrement caractérisés. Toutefois, il semble que les complexes CD3/TcR modulés soient internalisés, qu'ils suivent la voie d'endocytose dépendante des puits recouverts de clathrine [40] pour finalement atteindre les lysosomes où ils sont dégradés [41, 42]. La petite protéine G Rab5 qui contrôle les étapes précoces de l'endocytose dans d'autres modèles [43] est également impliquée dans la régulation de l'internalisation du CD3/TcR [44]. Il faut d'ailleurs noter, que l'activation par le CD3/TcR des lymphocytes T d'une souris exprimant un mutant dominant négatif de la petite protéine G Rab5, induit une prolifération et une synthèse d'IL-2 anormalement élevées [44]. Cela est corrélé avec le fait que, dans les lymphocytes $\mathrm{T}$ périphériques de ces souris, l'endocytose du complexe CD3/TcR induite par la stimulation du récepteur est très réduite.

Les mécanismes à l'origine de l'internalisation et de la dégradation des TcR stimulés ne sont pas connus. Plusieurs études ont suggéré qu'une protéine-kinase $\mathrm{C}$ (PKC) pourrait contrôler l'internalisation du CD3/TcR. Ainsi, l'activation de lymphocytes T par des esters de phorbol, qui activent les PKC, induit une internalisation du CD3/TcR [45-47]. Cette internalisation du TcR par des agents pharmacologiques qui activent certaines PKC, est dépendante de la phosphorylation du résidu
Ser126 présent dans le domaine intracytoplasmique de la chaîne CD3- $\gamma$ [47]. Toutefois, l'activation des PKC ne peut pas rendre compte de la diminution d'expression du TcR induite par la stimulation de ce récepteur. En effet, les esters de phorbol n'induisent pas de dégradation du TcR [45]. De plus, la mutation de la Ser126 de CD3- $\gamma$ n'empêche ni l'endocytose ni la dégradation du TcR induites par un agoniste alors qu'elle inhibe complètement l'internalisation induite par des esters de phorbol [48]. De nombreuses études ont conduit à des résultats contradictoires quant au rôle des tyrosine-kinases dans la dégradation du CD3/TcR. Pour certains, des molécules inhibant les tyrosine-kinases bloquent la modulation du TcR induite après stimulation de ce récepteur [42, 49, 50]. Pour d'autres, les tyrosine-kinases ne jouent de rôle ni dans l'endocytose ni dans la dégradation du CD3/TcR [48]. Enfin, l'activation du TcR induit son ubiquitinylation [51] d'une façon qui semble être dépendante des tyrosine-kinases [52]. Ces phénomènes d'ubiquitinylation sont à l'origine de la dégradation des protéines par le protéasome [53] mais contrôlent également l'endocytose de nombreux récepteurs et leur transport vers le compartiment lysosomial $[54,55]$.

La question: «Les acteurs de la transmission du signal par le complexe CD3/TcR jouent-ils un rôle dans la modulation et la dégradation du CD3/TcR? » reste donc entière. La stimulation du complexe CD3/TcR induit la phosphorylation sur des résidus Y des motifs ITAM présents dans les chaînes $\gamma \delta \varepsilon$ du CD3 et dans l'homodimère $\zeta$. Ces phosphorylations dépendent de l'activation de la tyrosine-kinase $\mathrm{p} 56^{\text {lck. }}$. Les phosphorylations des motifs ITAM permettent à leur tour le recrutement de la tyrosine-kinase ZAP-70 [56]. L'activation de ZAP-70 nécessite une nouvelle étape de phosphorylation sur le résidu Y493 qui semble être contrôlée par la tyrosine-kinase p56 $6^{\text {lck }}[57$, 58] (figure 4). Ce contrôle de l'activité de ZAP-70 par les membres de la famille Src semble assez spécifique de cette kinase puisque l'activation d'une autre kinase de la même famille, Syk, est indépendante de 
p56 $6^{\text {lck }}$ [58]. Deux groupes ont récemment montré que l'activation de la $\mathrm{p} 56^{\text {lck }}$ induit l'internalisation du TcR et son routage vers les compartiments de dégradation lysosomiaux [42, 59]. A la même époque, le groupe d'Antonio Lanzavecchia montrait que, dans une lignée Jurkat JCAM1.6 n'exprimant pas de p56 $6^{\text {lck }}$, on pouvait mettre en évidence une modulation et une dégradation du TcR induite par stimulation du TcR [48]. Il concluait donc que la modulation du TcR ne nécessite pas d'activation des lymphocytes $T$.

Dans d'autres modèles cellulaires, comme nous l'avons vu précédemment, la tyrosine-kinase Syk joue un rôle dans la dégradation de certains récepteurs après stimulation $[27,60]$. Un rôle de ZAP70 dans l'endocytose et la dégradation du complexe CD3/TcR, après stimulation antigénique de lymphocytes $\mathrm{T}$, peut donc être envisagé. Des expériences préliminaires réalisées dans des lymphocytes $\mathrm{T}$ issus d'un patient portant une mutation homozygote du gène zap70 [61] semblent indiquer que cette tyrosine-kinase contrôle des événements d'endocytose et de dégradation du complexe CD3/TcR (figure 3). Il reste cependant à comprendre quels sont les mécanismes mis en jeu. L'activité kinase de ZAP70 est-elle nécessaire ou sa propriété de protéine d'ancrage seule est-elle impliquée ? L'étape suivante sera de caractériser les effecteurs, substrats phosphorylés ou protéines associées, qui participent au transport et à la dégradation du CD3/TcR.

La comparaison des effecteurs de Syk impliqués dans les phénomènes de transport intracellulaire $\mathrm{du} \mathrm{BcR}$ et $\mathrm{FcR}$, et de présentation antigénique par ces récepteurs et des effecteurs de ZAP70 nécessaires à la dégradation du complexe CD3/TcR, sera particulièrement intéressante. En effet, les activités de ZAP70 et Syk sont différemment réglées et les substrats de ces kinases sont en partie spécifiques [62]

\section{TIRÉS À PART}

\section{RÉFÉRENCES}

1. Cambier JC. New nomenclature for the Reth motif (or ARH1/TAM/ARAM/ YXXL). Immunol Today 1995; 16: 110.

2. Wegener AM, Letourneur F, Hoeveler A, Brocker T, Luton F, Malissen B. The T cell receptor/CD3 complex is composed of at least two autonomous transduction modules. Cell 1992; 68: 83-95.

3. Bonnerot C, Amigorena S, Choquet D, Pavlovich R, Choukroun V, Fridman WH. Role of associated gamma-chain in tyrosine kinase activation via murine Fc gamma RIII. EMBO J 1992; 11 : 2747-57.

4. Reth M. Antigen receptor tail clue. Nature 1989; 338: 383-4.

5. Cambier JC. Antigen and Fc receptor signalling. The awesome power of the immunoreceptor tyrosine-based activation motif (ITAM). J Immunol 1995; 155 : 3281-5.

6. Agarwal A, Salem P, Robbins KC. Involvement of p72syk, a proteintyrosine kinase, in Fc gamma receptor signalling. $J$ Biol Chem $1993 ; 268: 15900-5$.

7. Kiener PA, Rankin BM, Burkhardt AL, et al. Cross-linking of Fc gamma receptor I (Fc gamma RI) and receptor II (Fc gamma RII) on monocytic cells activates a signal transduction pathway common to both Fc receptors that involves the stimulation of p72 Syk protein tyrosine kinase. J Biol Chem 1993; 268: 24442-8.

8. Kurosaki T, Takata M, Yamanashi Y, et al. Syk activation by the Src-family tyrosine kinase in the $\mathrm{B}$ cell receptor signalling. $J$ Exp Med 1994; 179: 1725-9.

9. Choquet D, Partiseti M, Amigorena S, Bonnerot C, Fridman WH, Korn H. Crosslinking of IgG receptors inhibits membrane immunoglobulin-stimulated calcium influx in B lymphocytes. J Cell Biol 1993; 121 : 35563.

10. Kanakaraj P, Duckworth B, Azzoni L, Kamoun M, Cantley LC, Perussia B. Phosphatidylinositol-3 kinase activation induced upon Fc gamma RIIIA-ligand interaction. JExp Med 1994; 179 : 551-8.

11. Kapeller R, Chakrabarti R, Cantley L, Fay F, Corvea S. Internalization of activated platelet-derived growth factor receptorphosphatidylinositol-3' kinase complexes: potential interactions with the microtubule cytoskeleton. Mol Cell Biol 1993; 13: 605263.

12. Liscovitch M, Cantley LC. Signal transduction and membrane traffic: the $\mathrm{PITP} /$ phosphoinositide connection. Cell 1995; 81 : 659-62.

13. Lanzavecchia A. Receptor-mediated antigen uptake and its effect on antigen presentation to class II-restricted T lymphocytes. Annu Rev Immunol 1990; 8: 773-93.

14. Cresswell P. Assembly, transport, and function of MHC class II molecules. Annu Rev Immunol 1994; 12 : 259-93.
15. Shaw AC, Mitchell RN, Weaver YK, Campos TJ, Abbas AK, Leder P. Mutations of immunoglobulin transmembrane and cytoplasmic domains : effects on intracellular signalling and antigen presentation. Cell $1990 ; 63: 381-92$.

16. Amigorena S, Salamero J, Davoust J, Fridman WH, Bonnerot C. Tyrosine-containing motif that transduces cell activation signals also determines internalization and antigen presentation via type III receptors for IgG. Nature 1992; 358: 337-41.

17. Aluvihare VR, Khamlichi AA, Williams GT, Adorini L, Neuberger MS. Acceleration of intracellular targeting of antigen by the B-cell antigen receptor: importance depends on the nature of the antigen-antibody interaction. EMBO J 1997; 16: 355362.

18. Weiser P, Müller R, Braun U, Reth M. Endosomal targeting by the cytoplasmic tail of membrane immunoglobulin. Science $1997 ; 276$ : 407-9.

19. Choquet D, Ku G, Cassard S, et al. Different patterns of calcium signalling triggered through two components of the B lymphocyte antigen receptor. J Biol Chem 1994; 269: 6491-7.

20. Clark MR, Campbell KS, Kazlauskas A, et $a l$. The $\mathrm{B}$ cell antigen receptor complex: association of Ig-alpha and Ig-beta with distinct cytoplasmic effectors. Science 1992; 258: $123-6$.

21. Flaswinkel H, Weiser P, Kim KM, Reth M. Signalling and internalization function of the B cell antigen receptor complex. In : Gupta S, Paul W, DeFranco A, Perlmutter R, eds. Mechanisms of lymphocyte activation and immune regulation. $V$. Molecular basis of signal transduction. Advances in experimental medicine and biology, vol. 135. New York-London: Plenum Press, 1994: 1-8.

22. Cassard S, Choquet D, Fridman WH, Bonnerot C. Regulation of ITAM signalling by specific sequences in Ig-beta B cell antigen receptor subunit. J Biol Chem 1996; 271 : 23786-91.

23. Bonnerot C, Lankar D, Hanau D, et al. Role of B cell receptor Ig alpha and Ig beta subunits in MHC class II-restricted antigen presentation. Immunity 1995; 3 : 335-47.

24. Lankar D, Briken V, Adler K, et al. Syk tyrosine kinase and $\mathrm{B}$ cell antigen receptor (BCR) immunoglobulin-alpha subunit determine BCR-mediated major histocompatibility complex class II-restricted antigen presentation. I Exp Med 1998; 188: 819-31.

25. Daeron M. Fc receptor biology. Annu Rev Immunol 1997; 15 : 203-34.

26. Amigorena S, Bonnerot C, Drake JR, et al. Cytoplasmic domain heterogeneity and functions of IgG Fc receptors in B lymphocytes. Science 1992; 256: 1808-12.

27. Bonnerot C, Briken V, Brachet V, et al. Syk protein tyrosine kinase regulates $\mathrm{Fc}$ receptor gamma-chain-mediated transport to lysosomes. EMBO J 1998; 17 : 4606-16. 


\section{Summary}

Intracellular trafficking and signalling of $\mathrm{FcR}, \mathrm{BcR}$ and $\mathrm{TcR}$

Cells of the immune system express a wide variety of receptors, defined as immunoreceptors. These receptors are involved in antigen recognition, $\mathrm{B}$ and $\mathrm{T}$ lymphocytes express clonally distributed receptors which recognize soluble antigen for the $\mathrm{B}$ cell receptor $(\mathrm{BcR})$ or peptide associated to major histocompatibility complex (MHC) molecules for the $\mathrm{T}$ cell receptor $(\mathrm{TcR})$. Moreover, $\mathrm{B}$ lymphocytes macrophages and dendritic cells, express receptors for antigen antibody complexes, which recognize the Fc portion of immunoglobulins (FcR). All these immunoreceptors share stricking functional and structural similarities. BcRs, TcRs and most FcRs are multichain complexes composed of a ligand binding module which consists of one or two chains determining the antigen specificity, and of a transducing module which consists of two to six chains containing one or several conserved motifs in their intracytoplasmic domain. These motifs called ITAM for immunoreceptor tyrosine-based activation motif couple receptors to intracellular effectors, such as tyrosine kinases, which induce a cascade of events

\section{RÉFÉRENCES}

28. Amigorena S, Lankar D, Briken V, Gapin L, Viguier M, Bonnerot C. Type II and III receptors for immunoglobulin G (IgG) control the presentation of different $\mathrm{T}$ cell epitopes from single IgG-complexed antigens. J Exp Med 1998; 187: 505-15.

29. Benhamou M, Ryba NJ, Kihara H, Nishikata H, Siraganian RP. Proteintyrosine kinase p72syk in high affinity IgE receptor signalling. Identification as a component of pp72 and association with the receptor gamma chain after receptor aggregation. Jiol Chem 1993; 268: 23318-24.

30. Donnadieu E, Cefaï D, Tan YP, Paresys G, Bismuth G, Trautmann A. Imaging early steps of human $T$ cell activation by antigen-presenting cells. J Immunol 1992; 148: 2643-53.

31. Valitutti S, Dessing M, Aktories K, Gallati $\mathrm{H}$, Lanzavecchia A. Sustained signalling leading to T cell activation results from prolonged $\mathrm{T}$ cell occupancy. Role of $\mathrm{T}$ cell actin cytoskeleton. J Exp Med 1995; 181: $577-84$.

$\mathrm{m} / \mathrm{s} n^{\circ} 8$-9, vol. 15, août-septembre 99 leading to cell activation. In parallel, expression of these immunoreceptors is finely regulated. These receptors are continuously and constitutively being internalized and recycled back to the cell surface. Moreover, recognition of the antigen by these immunoreceptors leads to the downregulation of the triggered receptors which are all internalized and transported along the endocytic pathway, some of them being adressed to the lysosomal compartment where they are degraded. The mechanisms controling the different steps of transport and targetting of the immunoreceptors to specialized compartments of the cells have recently been adressed but are still largely unknown. This review will focus on the potential role of some signalling molecules in the endosomal transport of the immunoreceptors. Indeed, as previously discussed they all share stricking similarities in terms of structure and function and the signalling pathways triggered by antigen binding to these different receptors also present similarities. It is thus possible that some of the mechanisms controlling their trans-

32. Li WH, Llopis J, Whitney M, Zlokarnik G, Tsien RY. Cell-permeant caged InsP3 esters shows that $\mathrm{Ca}^{2+}$ spike frequency can optimize gene expression. Nature 1998; 392: 936-41.

33. Dolmetsh RE, Xu K, Lewis RS. Calcium oscillations increase the efficiency and specificity of gene expression. Nature 1998; 392: 933-6.

34. Valitutti S, Müller S, Cella M, Padovan E, Lanzavecchia A. Serial triggering of many T cell receptors by a few peptide-MHC complexes. Nature 1995 ; 375 : 148-51.

35. Valitutti S, Müller S, Dessing M, Lanzavecchia A. Signal extinction and T cell repolarization in $\mathrm{T}$ helper cell-antigen-presenting cell conjugates. Eur J Immunol 1996; 26 : 2012-6.

36. Klausner RD, Lippincott-Schwartz J, Bonifacino JS. The T cell antigen receptor: insights into organelle biology. Annu Rev Cell Biol 1990 ; 6: 403-31.

37. Ono S, Ohno H, Saito T. Rapid turnover of the CD3 $\zeta$ chain independent of the TCR-CD3 complex in normal cells. Immunity $1995 ; 2$ : 639-44. port in the endocytic pathway may be common. However, we have to keep in mind that the physiological relevances of the endocytosis and transport of the different immunoreceptors are different. For the TcR, a rapid downregulation and degradation of the triggered receptors may be crucial to turn off a $\mathrm{T}$ cell response. Moreover the fact that a given CD3/TCR complex can only be triggered once ensure a strict control by the number of antigenic determinants of the length and strength of $T$ cell activation. In the case of BcR and FcRs, internalization and degradation are mainly involved in facilitating the endocytosis of soluble or complexed antigens. In both cases the receptors facilitate the access of antigens to specialized compartments where they are degraded into peptides which then associate with MHC class II molecules, thus allowing antigen presentation and immune response of $\mathrm{T}$ cell clones. It is thus evident that the unravelling of the mechanisms controlling endocytosis and transport of the immunoreceptors is of utmost interest in the understanding of immune response.

38. Nakagomi H, Peterson M, Magnusson I, et al. Decreased expression of the signal transducing $\zeta$ chains in tumor-infiltrating $\mathrm{T}$ cells and NK cells of patients with colorectal carcinoma. Cancer Res 1993; 53: 5610-2.

39. Otsuji M, Kimura Y, Aoe T, Okamoto Y, Saito T. Oxidative stress by tumor-derived macrophages suppresses the expression of CD3 z chain of T-cell receptor complex and antigen-specific T cell responses. Proc Natl Acad Sci USA 1996; 93 : 13119-24.

40. Boyer C, Auphan N, Luton F, et al. TCR/CD3 complex internalization following activation of a cytosolic $\mathrm{T}$ cell clone: evidence for a PKC-independent staurosporine sensitive step. Eur J Immunol 1991; 21 : 1623.

41. Valitutti S, Müller S, Salio M, Lanzavecchia A. Degradation of $T$ cell receptor (TCR)-CD3- $\zeta$ complexes after antigenic stimulation. J Exp Med 1997; 185 : 1859-64.

42. D'Oro U, Vacchio MS, Weissman AM, Ashwell JD. Activation of the Lck tyrosine kinase targets cell surface $\mathrm{T}$ cell antigen receptors for lysosomal degradation. Immunity 1997; 7 : 619-28.

Suite des références p. $930 \rightarrow$ 


\section{RÉFÉRENCES}

43. Gorvel JP, Chavrier P, Zerial M, Gruenberg J. rab5 controls early endosome fusion in vitro. Cell 1991; 64: 915-20.

44. André P, Boretto J, Hueber AO, Régnier-Vigouroux Aorvel JP, Ferrier P, Chavrier P. A dominant-negative mutant of the Rab5 GTPase enhances T cell signalling by interfering with TCR down-modulation in transgenic mice. J Immunol 1997; 159: 5253-63.

45. Krangel MS. Endocytosis and recycling of the CD3-T cell receptor complex. J Exp Med 1987; 165: 1141-59.

46. Minami Y, Samelson LE, Klausner RD. Internalization and cycling of the T-cell antigen receptor: role of protein kinase C. J Biol Chem 1987; 262 : 13342-6.

47. Dietrich J, Hou X, Wegener AM, Geisler C. CD3 gamma contains a phosphoserinedependent di-leucine motif involved in down-regulation of the $\mathrm{T}$ cell receptor. EMBO J 1994; 13: 2156-66.

48. Salio M, Valitutti S, Lanzavecchia A. Agonist-induced T cell receptor down-regulation: molecular requirements and dissociation from T cell activation. Eur J Immunol 1997; 27 : 1769-73.

49. Thuillier L, Pérignon JL, Seltz F, Griscelli C, Fischer A. Opposing effect of protein tyrosine kinase inhibitors on the monoclonal antibody induced internalization of
CD3 and CD4 antigens. Eur J Immunol 1991; $21: 2641-3$.

50. Luton F, Buferne M, Davoust J, SchmittVerhulst AM, Boyer C. Evidence for protein tyrosine kinase involvement in ligand-induced TCR/CD3 internalization and surface redistribution. J Immunol 1994; 153: 63-72.

51. Cenciarelli C, Hou D, Hsu KC, et al. Activation induced ubiquitination of the $\mathrm{T}$ cell antigen receptor. Science 1992; 257: 795-8.

52. Cenciarelli C Jr, KGW, Guo A, Weissman AM. T cell antigen receptor ubiquitination is a consequence of receptor-mediated tyrosine kinase activation. J Biol Chem 1996; 268 : 8709-13.

53. Weissman AM. Regulating protein degradation by ubiquitination. Immunol Today 1997; 18: 189-98.

54. Strous GJ, Kerkhof PV, Govers R, Ciechanover A, Schwartz AL. The ubiquitin conjugation system is required for ligandinduced endocytosis and degradation of the growth hormone receptor. EMBO J 1996 ; $15: 3806-12$.

55. Roth AF, Sullivan DM, Davis NG. A large PEST-like sequence directs the ubiquitination, endocytosis, and vacuolar degradation of the yeast $\alpha$-factor receptor. J Cell Biol 1998 ; 142 : 949-61.

56. Qian D, Weiss A. T cell antigen receptor transduction. Curr Opin Cell Biol 1997; 9: 205-12.
57. Chan AC, Dalton M, Johnson R, Kong GH, Wang T, Kurosaki RT. Activation of ZAP-70 kinase activity by phosphorylation of tyrosine 493 is required for lymphocyte antigen receptor function. $E M B O J 1995 ; 14$ : 2499-508.

58. Chu DH, Spits H, Peyron JF, Rowley RB, Bolen JB, Weiss A. The Syk protein kinase can function independently of CD45 or Lck in T cell antigen signalling. $E M B O J 1996$; 15 : 6251-61.

59. Lauristen JH, Christensen MD, Dietrich J, Kastrup J, Odum N, Geisler C. Two distinct pathways exist for down-regulation of the TCR. J Immunol 1998; 161 : 260-7.

60. Crowley MT, Costello PS, Fitzer-Attas CJ, et al. A critical role for Syk in signal transduction and phagocytosis mediated by Fc $\gamma$ receptors on macrophages. J Exp Med 1997; 186: $1027-39$

61. Hivroz C, LeDeist F, Fischer A. Le déficit en tyrosine kinase ZAP-70: un modèle de déficit immunitaire héréditaire pour l'analyse de l'activation et de la différenciation des lymphocytes T. Med Sci 1995; 11: 26872 .

62. Latour S, Chow LML, Veillette A. Differential intrinsic enzymatic activity of Syk and Zap-70 protein-tyrosinekinase. I Biol Chem 1996; 271 : 22782-90. 